\title{
Family history: a vital predictor of cardiovascular health
}

\author{
Jaspinder kaur \\ Medical Officer, Exservicemen Contributory Health Scheme Polyclinic, Sultanpur Lodhi, Kapurthala, Punjab-144626 \\ E-mail: mailtojaspinder@yahoo.in
}

\begin{abstract}
Objective: Family history, one of the traditional tools in clinical medicine, is frequently neglected which can be used to identify persons at increased cardiovascular disease (CVD) risk. The present study aimed to determine the influence of family history on cardiovascular health.

Methodology: A cross sectional study was conducted on the retired defense personnel to study the relation of socio-demographic variables, physical activity, body mass index, sleep, stress and metabolic syndrome with family history from Jun to Oct, 2013. Chi Square test was used with statistical significance of $\mathrm{P}$ value $<0.05$.

Results: A positive family history was reported among $32.77 \%$ of the study subjects with statistically significant higher recording by females $(60.87 \%$; P <0.01), those who were aged 20-60years $(62.60 \%$; $\mathrm{P}<0.001)$, and had higher education level $(42.61 \%$; $\mathrm{P}<0.05)$. A statistically significant stress $(29.56 \%$; $\mathrm{P}<0.001)$, sedentary lifestyle $(72.17 \%$; $\mathrm{P}<0.05)$ and insomnia $(29.56 \%)$ was reported among subjects reporting positive family history. A statistically significant prevalence of metabolic syndrome $(36.53 \%$; $\mathrm{P}<0.05)$, hypertension (56.52\%; $\mathrm{P}<0.01)$, obesity $(54.78 \%)$, dyslipidemia (33.05\%; $\mathrm{P}<0.05)$ and dysglycemia $(31.31 \%$; $\mathrm{P}<0.05)$ was more in subjects reporting positive than negative family history (metabolic syndrome: 23.73\%; $(\mathrm{P}<0.05)$; hypertension: $41.52 \%(\mathrm{P}<0.01)$; obesity: $50.00 \%$; dyslipidemia: $21.61 \%(\mathrm{P}<0.05)$; dysglycemia: $21.19 \%(\mathrm{P}<0.05))$.

Conclusions: A statistical association between positive family history and metabolic syndrome shows CVD susceptibility which prompts to utilize every opportunity to involve concerned families in health education by promoting healthy lifestyle changes in their diet and physical activity.
\end{abstract}

Keywords: Cardiovascular Disease, Family History, Metabolic Syndrome.

\section{Introduction}

Cardiovascular disease (CVD) is a complex disease involving interactions among genes, environment and behaviors (Bertuzzi et al. 2003). In terms of attributable deaths; the leading CVD risk factor that can be controlled, treated or modified is raised blood pressure (to which $13 \%$ of global deaths is attributed), followed by tobacco use $(9 \%)$, raised blood glucose $(6 \%)$, physical inactivity $(6 \%)$, and overweight and obesity (5\%) (World Health Organization 2011). However, there are some risk factors in addition to these modifiable risk factors that cannot be changed or treated which includes age, gender and family history.

It is well known that females are prone to coronary heart disease at least 10 years later than men. A positive family history of CVD increases the risk further, where if a first-degree blood relative has had coronary heart disease or stroke before the age of 55 years (for a male relative) or 65 years (for a female relative) (Chobanian et al. 2003). Compared to persons with no family history, those with a family history of CVD are 1.5 to 9.0 times more likely to develop CVD, depending on the relation, number and age of onset of the relative(s) (McCusker et al. 2004). Moreover, if both parents have suffered from heart disease before the age of 55, the risk of developing heart disease can rise to $50 \%$ compared to the general population. A chance of having a stroke is increased if first-degree relatives have had strokes especially at a young age, and the risk further increase if relative is a mother. Moreover, inheriting hypertension is a key factor in the familial link of ischemic stroke. Another inherited condition known as familial hypercholesterolemia will build up increased low-density lipoprotein cholesterol levels in the blood and subsequently leads to coronary heart disease. Type 2 diabetes has a genetic component, and considered as a risk factor for the development of both diabetes mellitus and cardiovascular disease especially if one of the parents developed diabetes mellitus (World Health Federation 2014).

The perception of family history, and thus individual risk, is particularly important for health promotion (Hunt et al. 2000). One might expect that individuals with a family history of CHD are consequently at a higher risk for the disease, and must be more aware of healthy behaviors. However, individuals at risk for CHD do not always adopt appropriate health behaviors, either due to the individual's inability to change their habits or to simple ignorance. A high prevalence of CVD and its far reaching societal and economic consequences prompts need to trace the risk factors in firstdegree relatives of individuals with CHD, particularly those who have suffered a premature event, as an approach for CHD prevention and to have a notable public health impact (Chow et al. 2007). However, little is known about the type of preventive recommendations offered by clinicians to their patients with a family history of CVD but without CVD, and about the extent to which patients follow recommendations to reduce their CVD risk. Taking family history is one of the traditional tools in clinical medicine to identify person who are at increased risk for CVD, and who thus may be receptive to and benefit more from interventions aimed at preventing CVD than patients with no family history; however, it is frequently neglected. 
Thus, an orientation need for those with positive cardiovascular family history on how to adopt healthier lifestyles is of paramount interest in public health. Assessing the prevalence of other cardiovascular risk factors in subjects with positive cardiovascular family history would further help in providing this orientation. Hence, the present comparative study of socio-demographic variables and cardiovascular parameters in subjects with positive and negative family history was designed.

\section{Materials and methods}

\subsection{Design overview}

A cross-sectional study was designed to observe the appearance of other cardiovascular risk factors on the basis of family history. The selection for the present study was subjects who had been retired from the defense services; their family members comprising spouse, parents and children; both genders aged above 20 years; and those had attended the polyclinic from June, 2013 to Oct, 2013. Under the Exservicemen Contributory Health Scheme (ECHS), all registered members are entitled to free at-the-pointof-access medical attention and services from the polyclinic being located at Sultanpur Lodhi, Kapurthala, Punjab (India). Institutional ethical committee approval was obtained prior to the study start, and informed written consent was taken from all the recruited subjects. The results were analyzed by Chi Square test with $\mathrm{P}$ value $<0.05$ as statistically significant.

\subsection{Information sources}

The multi-parameter and pre-tested data collection forms were designed on which the clinical history data, physical examination and biochemical tests were recorded. Questionnaire, Measuring Tape, Weighing Scale, BP Apparatus, Stethoscope, bacteriological incubator, Erba glucose kit (GOD-POD method, end point), Erba triglyceride Des kit (GPO-Trinder method, end point) and cholesterol kit (Phosphotungstic acid method, end point) were used to collect the information. All instruments were checked for calibration before using them.

\subsection{Cardiovascular family history}

Subjects were asked if their mother, father, siblings, or children have had CVD defined as a heart attack, myocardial infarction or cardiac procedures (coronary bypass surgery, balloon angioplasty, intracoronary stenting); or stroke, cerebral hemorrhage or brain attack; or diabetes or high blood sugar. The family history was defined as "positive" when a person was able to recollect the history of CVD; and "negative" if the interviewed person reported the absence of a specific condition, and/or didn't know whether any relatives had ever been affected with CVD.

\subsection{Survey questionnaires}

A structured in-person interview was conducted to record sociodemographic variables and cardio-metabolic risk factors. Metabolic syndrome was defined on the basis of consensus statement for Asians Indians with three out of five variables abnormal for the diagnosis: Obesity $>25.00 \mathrm{~kg} / \mathrm{m}^{2}$, fasting blood glucose $>100 \mathrm{mg} / \mathrm{dl}$ (>5.6mmol/1), hypertension $\geq 130 / \geq 85 \mathrm{mmHg}$, triglycerides(TGs) $>150 \mathrm{mg} / \mathrm{dl}(>1.7 \mathrm{mmol} / \mathrm{l})$ and/or High Density Lipoprotein Cholesterol(HDL-C) $<40 \mathrm{mg} / \mathrm{dl} \quad(<1.03 \mathrm{mmol} / \mathrm{l})$ in men or $<50 \mathrm{mg} / \mathrm{dl}$ $(<1.29 \mathrm{mmol} / \mathrm{l})$ in women. It includes those previously diagnosed with hypertension, high TGs, low HDL-C, impaired fasting glucose (IFG), impaired glucose tolerance (IGT) or diabetes mellitus and being on treatment for these disorders (Misra et al. 2009). Men alcohol intake is limited to <2 drinks per day; and for women and lighter weight persons, it is limited to $<1$ drink per day ( 1 drink $=1 / 2 \mathrm{oz}$ or $15 \mathrm{ml}$ ethanol (e.g., $12 \mathrm{oz}$ beer, $5 \mathrm{oz}$ wine, $1.5 \mathrm{oz}$ 80-proof whiskey)) (Chobanian et al. 2003). Subjects exceeding their limit were categorized under "Current/Yes" group. Job strain, social constraints, financial un-stability, health issues, and family distress were included under "stress" which significantly affects the daily life activities. Sleep adequacy was evaluated on the basis of sleep duration (7 to 8 hours), difficulty in initiating and maintaining sleep, and early awakenings. The regular aerobic physical activity (e.g., brisk walking) of at least 30 minutes per day for most days of the week was considered adequate (Chobanian et al. 2003).

\subsection{Measurements}

Height was determined using a wall mounted non-extendable measuring tape with subjects standing in an erect barefoot position, arms by side and feet together with $0.1 \mathrm{~cm}$ precision. Weight measurements were taken with each subject standing at the centre of the weighing scale in light clothing with no shoes and socks with $0.5 \mathrm{~kg}$ precision. Body mass index (BMI) was calculated as weight per square meter $\left(\mathrm{kg} / \mathrm{m}^{2}\right)$ and classified on the basis of consensus statement: Normal weight $\left(18.00-22.99 \mathrm{~kg} / \mathrm{m}^{2}\right)$, Overweight $\left(23.00-24.99 \mathrm{~kg} / \mathrm{m}^{2}\right)$ and Obesity $\left(>25.00 \mathrm{~kg} / \mathrm{m}^{2}\right)$ (Misra et al. 2009). Blood pressure was measured in the right arm with the subject rested for 5 minutes using a standard mercury sphygmomanometer and suitable calibrated cuff. A venous blood sample was obtained from all the pre-informed individuals after $8-10$ hours of fasting to measure blood glucose, TGs and HDL-C levels.

\section{Results}

All patients $(\mathrm{N}=351)$ were divided on the basis of cardiovascular family history: positive $(\mathrm{N}=115 ; 32.77 \%)$ and negative $(\mathrm{N}=236$; $67.24 \%$ ). Table 1 displays $13.04 \%, 49.56 \%$ and $37.39 \%$ of subjects with positive family history were in 20-40years, 41-60years, and $>60$ years of age group; and those with negative family history had $05.93 \%, 36.44 \%$ and $57.63 \%$ for the same age groups, respectively. It shows statistically significant subjects who reported positive family history were in 20-60years of age group $(62.60 \%$; $\mathrm{P}<0.001$ ), and those reporting negative family history were $>60$ years old $(57.63 \%$; $\mathrm{P}<0.001)$, respectively. A statistically significant females $(60.87 \%$; $\mathrm{P}<0.01)$ had more frequently stated positive family history than males $(54.66 \%$; $\mathrm{P}<0.01)$. Further, a statistical significant association was found between positive family history and higher education level $(42.61 \%$; $\mathrm{P}<0.05)$; where subjects with no/little, primary, secondary and graduation had reported $20.87 \%, 36.52 \%, 36.52 \%$ and $06.09 \%$ of positive family history; and $35.59 \%, 28.81 \%, 31.78 \%$ and $03.81 \%$ of them had stated negative family history for the same education categories, respectively. Similarly, positive family history was more stated by subjects belonging to middle $(67.83 \%)$ than upper $(61.44 \%)$ social class. However, the study found no significant differences between the prevalence of positive family history on the basis of employment status.

Table 1: Comparisons of the Socio-Demographic Variables in the All Study Subjects

\begin{tabular}{|c|c|c|c|}
\hline \multirow[b]{2}{*}{ Category } & \multicolumn{2}{|c|}{ Cardiovascular family history } & \multirow[b]{2}{*}{$P$ value } \\
\hline & $\begin{array}{l}\text { Positive } \\
\text { (115) }\end{array}$ & $\begin{array}{l}\text { Negative } \\
(236)\end{array}$ & \\
\hline \multicolumn{4}{|c|}{ AGE (years) } \\
\hline $20-40$ & $13.04(15)$ & $05.93(14)$ & \multirow{3}{*}{$\begin{array}{l}14.19 \\
(<0.001)\end{array}$} \\
\hline $41-60$ & $49.56(57)$ & $36.44(86)$ & \\
\hline$>60$ & $37.39(43)$ & $57.63(136)$ & \\
\hline \multicolumn{4}{|c|}{ SEX } \\
\hline Male & $39.14(45)$ & $54.66(129)$ & \multirow{2}{*}{$7.45(<0.01)$} \\
\hline Female & $60.87(70)$ & $45.34(107)$ & \\
\hline \multicolumn{4}{|c|}{ EDUCATION } \\
\hline No/Little & $20.87(24)$ & $35.59(84)$ & \multirow{4}{*}{$8.31(<0.05)$} \\
\hline Primary & $36.52(42)$ & $28.81(68)$ & \\
\hline Secondary & $36.52(42)$ & $31.78(75)$ & \\
\hline Graduation & $06.09(07)$ & $03.81(9)$ & \\
\hline \multicolumn{4}{|c|}{ SOCIO ECONOMIC STATUS } \\
\hline Middle & $67.83(78)$ & $61.44(145)$ & \multirow{2}{*}{1.35} \\
\hline Upper & $32.17(37)$ & $38.56(91)$ & \\
\hline
\end{tabular}




\begin{tabular}{|c|c|c|c|}
\hline \multicolumn{4}{|c|}{ OCCUPATION } \\
\hline $\begin{array}{l}\text { Homemaker or Re- } \\
\text { tired }\end{array}$ & $70.43(81)$ & $70.76(167)$ & \multirow{2}{*}{0.04} \\
\hline Employed & $29.56(34)$ & $29.24(69)$ & \\
\hline
\end{tabular}

Table 2 reflects $20.87 \%, 24.35 \%$ and $54.78 \%$ of subjects with positive family history were in normal, overweight and obesity ranges; and those reporting negative family history had $30.93 \%$, $19.07 \%$ and $50.00 \%$ for the same groups, respectively. It shows a higher prevalence of obesity $(54.78 \%)$ and normal weight (30.93\%) among subjects reporting positive and negative family history, respectively. Figure 1 further reflects that obesity increases at a higher rate as age advances in subjects stating positive family history.

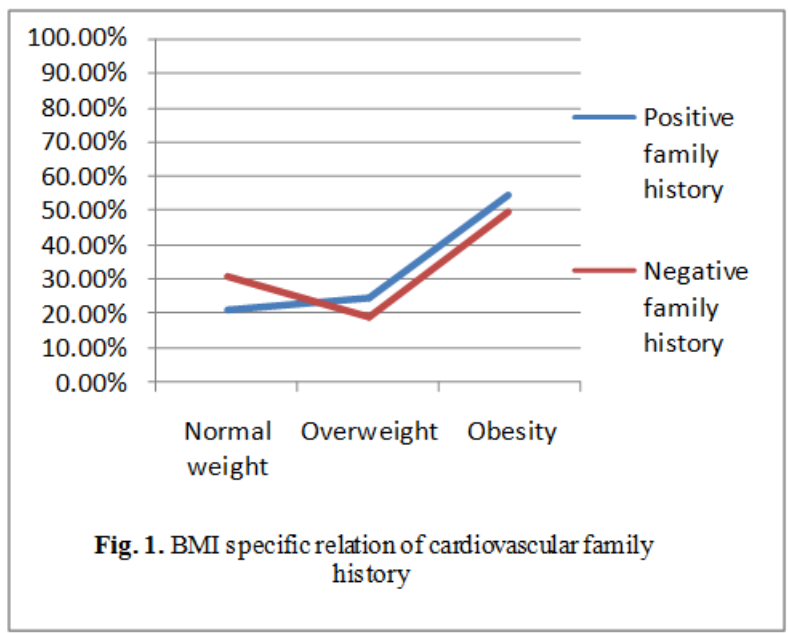

Table 2 further reveals subjects with positive family history $(29.56 \%)$ had a higher prevalence of insomnia than negative family history subjects $(26.69 \%)$. No significant relation of family history and alcohol consumption was found. Contrarily, a statistically significant stress levels were reported among subjects with positive $(29.56 \% ; \mathrm{P}<0.001)$ than negative $(13.14 \% ; \mathrm{P}<0.001)$ family history. Moreover, statistically significant subjects stating positive family history leads a sedentary lifestyle $(72.17 \%$; $\mathrm{P}<0.05)$, and those with negative family history reports active lifestyle $(40.25 \% ; \mathrm{P}<0.05)$.

Table 2: Comparison of the Other Cardiovascular Risk Factors in Subjects with Positive and Negative Family History*

\begin{tabular}{|c|c|c|c|}
\hline \multirow[t]{2}{*}{ Category } & \multicolumn{2}{|c|}{ Cardiovascular family history } & \multirow[t]{2}{*}{$P$ value } \\
\hline & Positive (115) & Negative (236) & \\
\hline \multicolumn{4}{|c|}{ BODY MASS INDEX } \\
\hline Normal & $20.87(24)$ & $30.93(73)$ & \multirow{3}{*}{4.22} \\
\hline Overweight & $24.35(28)$ & $19.07(45)$ & \\
\hline Obesity & $54.78(63)$ & $50.00(118)$ & \\
\hline \multicolumn{4}{|c|}{ ALCOHOL CONSUMPTION } \\
\hline Yes & $23.48(27)$ & $24.58(58)$ & \multirow{2}{*}{0.06} \\
\hline No & $76.52(88)$ & $75.42(178)$ & \\
\hline \multicolumn{4}{|c|}{ SLEEP ADEQUACY } \\
\hline Adequate & $70.43(81)$ & $73.30(173)$ & \multirow{2}{*}{0.31} \\
\hline In adequate & $29.56(34)$ & $26.69(63)$ & \\
\hline \multicolumn{4}{|c|}{ STRESS LEVELS } \\
\hline Significant & $29.56(34)$ & $13.14(31)$ & \multirow[t]{2}{*}{$13.83(<0.001)$} \\
\hline Insignificant & $70.44(81)$ & $86.86(205)$ & \\
\hline \multicolumn{4}{|c|}{ PHYSICAL ACTIVITY } \\
\hline Adequate & $27.83(32)$ & $40.25(95)$ & \multirow{2}{*}{$5.17(<0.05)$} \\
\hline Inadequate & $72.17(83)$ & $59.75(141)$ & \\
\hline
\end{tabular}

Table 3 depicts statistically significant higher prevalence of metabolic syndrome and its components in subjects stating positive $(36.53 \%$; $\mathrm{P}<0.05)$ than negative $(23.73 \%$; $\mathrm{P}<0.05)$ family history. It further shows subjects reporting positive family history had statistically significant higher prevalence of hypertension (56.52\%; $\mathrm{P}<0.01)$, obesity $(54.78 \%)$, dyslipidemia $(33.05 \%$;
$\mathrm{P}<0.05)$, and dysglycemia $(31.31 \%$; $\mathrm{P}<0.05)$ than individuals with negative family history (hypertension: $41.52 \%(\mathrm{P}<0.01)$; obesity: $50.00 \%$; dyslipidemia: $21.61 \% \quad(\mathrm{P}<0.05)$, and dysglycemia: $21.19 \%(\mathrm{P}<0.05))$. Figure 2 further compares the graphical presentation of metabolic syndrome and its components among subjects reporting positive and negative family history.

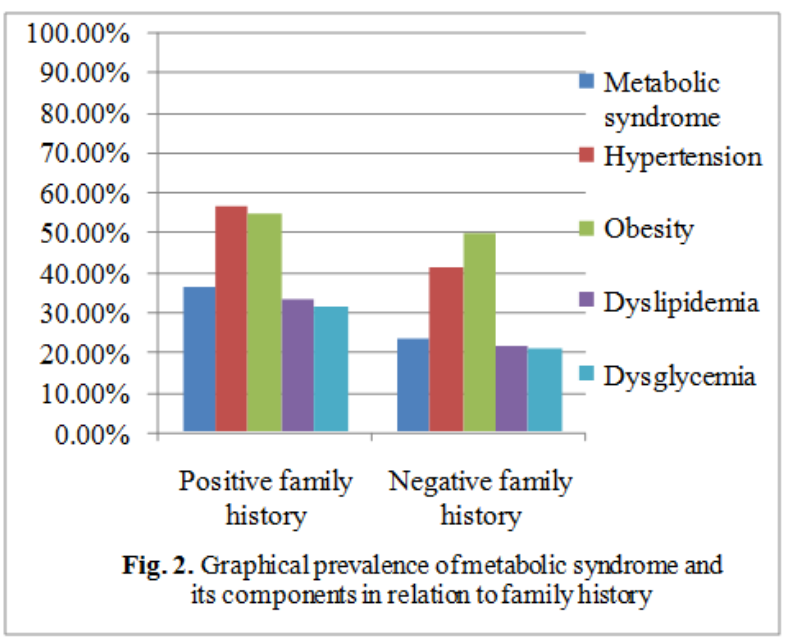

Table 3: Comparison of the Metabolic Syndrome And Its Components in All the Study Subjects ${ }^{*}$

\begin{tabular}{llllll}
\hline \multirow{2}{*}{ Category } & \multicolumn{5}{c}{ Cardiovascular family history } \\
& Noritive $(115)$ & \multicolumn{2}{c}{ Negative $(236)$} & P value \\
& Normal & Diseased & Normal & Diseased & \\
\hline Metabolic & 63.48 & 36.53 & 76.27 & 23.73 & 6.31 \\
Syndrome & $(73)$ & $(42)$ & $(180)$ & $(56)$ & $(<0.05)$ \\
Hypertension & 43.48 & 56.52 & 58.47 & 41.52 & 6.98 \\
& $(50)$ & $(65)$ & $(138)$ & $(98)$ & $(<0.01)$ \\
Obesity & 45.22 & 54.78 & 50.00 & 50.00 & 0.71 \\
& $(52)$ & $(63)$ & $(118)$ & $(118)$ & 5.36 \\
Dyslipidemia & 66.96 & 33.05 & 78.39 & 21.61 & $(<0.05)$ \\
& $(77)$ & $(38)$ & $(185)$ & $(51)$ & 4.31 \\
Dysglycemia & 68.70 & 31.31 & 78.81 & 21.19 & $(<0.05)$ \\
\hline & $(79)$ & $(36)$ & $(186)$ & $(50)$ & \\
\hline
\end{tabular}

Table 4 revealed $21.74 \%, 23.48 \%, 13.05 \%$ and $59.14 \%$ of subjects inherited or shared positive family history from their mother, father, both parents, and siblings, respectively. Moreover, $100 \%$, $33.05 \%$ and $05.22 \%$ of subjects had one, two, and three and more relatives affected in their families, respectively.

Table 4: Characteristics of Subjects with Positive Cardiovascular Family History $(\mathrm{N}=115)$

\begin{tabular}{lcc}
\hline Category & Percentage & Number of subjects \\
\hline & RELATIVE AFFECTED \\
Mother & 21.74 & 25 \\
Father & 23.48 & 27 \\
Both parents & 13.05 & 15 \\
Sibling & 59.14 & 68 \\
& NUMBER OF RELATIVES AFFECTED \\
One & 100 & 115 \\
Two & 33.05 & 38 \\
Three and more & 5.22 & 6 \\
\hline
\end{tabular}

\section{Discussion}

Self-reported family histories of disease, defined as the recollection of a diagnosis in a first-degree relative, are easy to ascertain, and several studies have demonstrated the accuracy of such histories (Allen et al. 1987). Reporting of a family history depends on the prevalence of the diseases, the number of family members affected, availability of diagnostic facilities, health seeking behavior of patients, and on how familiar they are with diagnoses of their family members (Van der Sande et al. 2001).

The current study reported positive family history among $32.77 \%$ of the study subjects, and negative or unaware status in $67.24 \%$ of 
the subjects. Similarly, Zlot et al. (2010) found 38\% of the study participants were reporting a family history of CVD. Furthermore, McCusker et al. (2004) has given a national estimate of $43 \%$ for all the U.S. adults, with and without CVD, who reported having a family history of CVD. The Eurospire epidemiological survey (1997) has indicated that up to $52 \%$ of the population has positive family history of CHD, whilst $37 \%$ have a family history of premature CHD. Various studies has shown that high recording levels was found for some of the risk factors such as blood pressure, cholesterol and smoking, but levels of family history recording ranged from 19 to $81 \%$ in patients aged 60-75, and was dependen on the practice (Sheerin et al. 2007). However, the level and quality of recording was still low, and suggested that the addition of more systematic family history may increase the proportion of individuals identified with high cardiovascular risk for targeting of preventive interventions by up to $40 \%$ (Qureshi et al. 2012).

The present study (Table 1) observed that subjects reporting positive family history were younger (20-60years; $62.60 \%)$ than those stating negative status (>60years; 57.63\%). Tavares et al. (2011) reported the proportion of subjects with a family history of CHD was significantly more in $\geq 40$ years than $18-39$ years of age. Zlot et al. (2010) further noticed persons with a positive family history were older with a mean age of 51.2 years than those without a family history (mean age $=42.0$ years). Moreover, Dhiman et al. (2014) showed patients aged 50-59 and 60-69 had higher odds of having their family history recorded compared to those aged 20 29 and above 80.

Females $(60.87 \%)$ were more frequently recorded with positive family history than males (54.66\%). Similarly, Van der Sande et al. (2001) and Zlot et al. (2010) found a higher reporting of family history by females in their study population. A positive association between family history and high education level $(42.61 \%$; $\mathrm{P}<0.05)$ in the current study was found consistent to Van der Sande et al. (2001). Conversely, Tavares et al. (2011) observed more reporting of positive family history by less educated subjects. However, it has been reported that health care and health behaviors did not differ significantly between individuals with and without a family history of CHD, which might be contributed to non-receiving of health behavior recommendations or information on their health risk for developing the disease by individuals with CHD family history. Nevertheless, having a perception of risk does not necessarily translate into positive behavioral changes. Some research suggests that increased perception of familial risk does not lead to changed behavior; where some people may even adopt a fatalistic outlook and make no efforts to decrease their risk (Kip et al. 2002). On the other hand, it has been shown that having a close family member with a chronic disease may increase perception of risk and encourage health-promoting behaviors, such as weight control and fruit and vegetable consumption (Baptiste-Roberts et al. 2007) A statistically significant sedentary lifestyle was reported by subjects with positive family history $(72.17 \%$; $\mathrm{P}<0.05)$. Similarly, Endre et al. (1994) noticed lower levels of physical activity among the family members of hypertensives. However, having witnessed the burden of these diseases within the family, people are more likely to be motivated to modify their behavior; their motivation for behavior change will therefore be higher than that among the general population (Van der Sande et al. 2001).

The present study observed insomnia more among subjects reporting positive $(29.56 \%)$ than negative family history $(26.69 \%)$. Similarly, Williams et al. (2007) found short sleepers were more prone to have a family history of diabetes and were more likely to have a history of hypertension compared to subjects with sleep durations of $\geq 6$ hours. Furthermore, a statistically significant stress was observed among subjects with positive $(29.56 \%$; $\mathrm{P}<0.001)$ than negative $(13.14 \%$; $\mathrm{P}<0.001)$ family history in the current study. Similarly, Hamang et al. (2011) reported that history of a recent sudden cardiac arrest in the family was independently related to general anxiety and depression, regardless of disease status which might be contributed to fear of living with the underlying genetic risk of a life-threatening disorder and the uncertainty regarding cardiac symptoms, especially among patients with higher levels of heartfocused anxiety.

A statistically significant (Table 3) metabolic syndrome and its components was observed in subjects with positive $(36.53 \%$; $\mathrm{P}<0.05)$ than negative $(23.73 \%$; $\mathrm{P}<0.05)$ family history. Similarly, Dallongeville et al. (2006) observed metabolic syndrome association with parental premature CVD independently of other classical cardiovascular risk factors, suggesting that metabolic syndrome is a contributor to the familial aggregation of premature CVD. As the metabolic syndrome clusters several metabolic disorders, one possibility could be that parents concentrate similar factors which results in an increased CVD risk. Furthermore, the present study found subjects with positive family history had statistically significant higher prevalence of hypertension $(56.52 \%$; $\mathrm{P}<0.01)$, obesity $(54.78 \%)$, dyslipidemia $(33.05 \%$; $\mathrm{P}<0.05)$ and dysglycemia $(31.31 \%$; $\mathrm{P}<0.05)$ than individuals with negative family history (hypertension: $41.52 \%(\mathrm{P}<0.01)$; obesity: $50.00 \%$; dyslipidemia: $21.61 \%(\mathrm{P}<0.05)$, and dysglycemia: $21.19 \% \quad(\mathrm{P}<0.05))$. Grotto et al. (2003) has further shown similar association between individual components of the metabolic syndrome such as body weight, glucose intolerance, elevated triglycerides or hypertension, and parental CVD. Conversely, Zolt et al. (2010) reported that although family history of CVD was associated with high cholesterol; but, no association of diabetes or obesity was found with positive history.

It has been suggested that positive family histories might be underestimated, particularly for hypertension, which may often remain subclinical as long as damage to target organs remains within acceptable limits for an affected individual. Thus, normotensive people with a family history have been classified as "normotensive hypertensives". However, underreporting might be less marked for diabetes, which tends to manifest itself earlier than hypertension, and for obesity, which is a visible condition and less dependent for its diagnosis on medical testing (Van der Sande et al. 2001).

The study further reveals $21.74 \%, 23.48 \%, 13.05 \%$ and $59.14 \%$ of subjects inherited or shared positive family history from their mother, father, both parents and siblings, respectively (Table 4). Furthermore, Harrap et al. (2000) has shown that shared environmental effects on CHD risk are stronger for sibling pairs than parent-offspring pairs and thus contributing to familial aggregation of CHD. Sesso et al. (2001) has noticed maternal history of myocardial infarction (MI) appears to predict CVD at least as strongly as paternal history, and even at older ages of maternal MI.

Limitations: A cross-sectional design could limit the control, causality, and generalizability of the study. Another potential limitation is lack of validation of self-reports of family history and age at onset of CVD among family members which might subject to recall bias and under-reporting. Yet, despite under-reporting, positive disease associations are consistently observed, and as a result, use of family history can help to stratify disease risk in the population. A longitudinal analysis might further enhance the ability to examine risk reduction practices over time.

\section{Conclusion}

A statistical association between positive family history and metabolic syndrome shows CVD susceptibility. Hence, health professionals who deal with patients with cardiovascular diseases should utilize every opportunity to involve the concerned families in health education by promoting lifestyle changes in their diet and physical activity which might contribute to the control and prevention of cardiovascular diseases.

\section{Acknowledgement}

I acknowledge all the patients who gave their permission to be a part of this study and the entire staff of the polyclinic for their 
consistent support; and Ms Manjit Kaur for her assistance in the statistical analysis.

Financial support: None.

Conflict of interest: None.

\section{References}

[1] Allen MT, Sherwood A, Obrist PA, Crowell MD \& Grange LA (1987), Type A behavior pattern, parental history of hypertension, and cardiovascular reactivity in college males. Health Psychology 6, 113-130.

[2] Baptiste-Roberts K, Gary TL, Beckles GL, Gregg EW, Owens M, Porterfield D \& Engelgau MM et al (2007), Family history of diabetes, awareness of risk factors, and health behaviors among African Americans. Is J Public Health 97, 907-912?

[3] Bertuzzi M, Negri E, Tavani A \& La vecchia C (2003), Family history of ischemic heart disease and risk of acute myocardial infarction. Prev Med. 37, 183-187.

[4] Chobanian AV, Bakris GL, Black HR, Cushman WC, Green LA, Izzo JL Jr., Jones DW, Materson BJ, Oparil S, Wright JT Jr, Roccella EJ, Joint National Committee on Prevention, Detection, Evaluation, and Treatment of High Blood Pressure; National Heart, Lung, and Blood Institute \& National High Blood Pressure Education Program Coordinating Committee (2003), Seventh report of the Joint National Committee on Prevention, Detection, Evaluation, and Treatment of High Blood Pressure. Hypertension 42, 1206-1252.

[5] Chow CK, Pell AC, Walker a, O'Dowd C, Dominiczak AF \& Pell JP (2007), Families of patients with premature coronary heart disease: an obvious but neglected target for primary prevention. BMJ 335, 481485.

[6] Dallongeville J, Grupposo MC, Cottel D, Ferrie`res J, Arveiler D, Bingham A, Ruidavets JB, Haas B, Ducimetie`re P \& Amouyel P (2006), Association between the metabolic syndrome and parental history of premature cardiovascular disease. European Heart Journal 27, 722-728.

[7] Dhiman P, Kai J, Horsfall L, Walters K \& Qureshi N (2014), Availability and Quality of Coronary Heart Disease Family History in Primary Care Medical Records: Implications for Cardiovascular Risk Assessment. PLoS ONE 9, e81998.

[8] Endre T, Mattiasson I, Berglund G \& Hulthen L (1994), Insulin resistance is coupled to low physical fitness in normotensive men with a family history of hypertension. Journal of Hypertension 12, 81-88.

[9] EUROSPIRE study group (1997), A European Society of Cardiology survey of secondary preventions of coronary heart disease: principal results. Eur Heart J. 18, 1569-1582.

[10]Global Atlas on Cardiovascular Disease Prevention and Control Mendis S, Puska P \& Norrving B editors. World Health Organization (in collaboration with the World Heart Federation and World Stroke Organization), Geneva 2011.

[11]Grotto I, Huerta M, Kark JD, Shpilberg O \& Meyerovitch J (2003), Relation of parental history of coronary heart disease to obesity in young adults. Int J Obes Relat Metab Disord 27, 362-368.

[12] Hamang A, Eide GE, Rokne B, Nordin K \& Øyen N (2011), General anxiety, depression, and physical health in relation to symptoms of heart-focused anxiety- a cross sectional study among patients living with the risk of serious arrhythmias and sudden cardiac death. Health and Quality of Life Outcomes 9, 100.

[13]Harrap SB, Stebbing M, Hopper JL, Hoang HN \& Giles GG (2000), Familial patterns of covariation for cardiovascular risk factors in adults: The Victorian Family Heart Study. Am J Epidemiol 152, 704 715 ?

[14]Hunt K, Davison C, Emslie C \& Ford G (2000), Are perceptions of a family history of heart disease related to health-related attitudes and behaviour? Health Educ Res. 15, 131-143.

[15]Kip KE, McCreath HE, Roseman JM, Hulley SB \& Schreiner PJ (2002), Absence of risk factor change in young adults after family heart attack or stroke: the CARDIA Study. Is J Prev Med. 22, 258266 ?

[16]McCusker ME, Yoon PW, Gwinn M, Malarcher AM, Neff L \& Khoury MJ (2004), Family history of heart disease and cardiovascular disease risk-reducing behaviours. Genet Med. 6, 153-158.

[17]Misra A, Chowbey P, Makkar BM, Vikram NK, Wasir JS, Chadha D, Joshi SR, Sadikot S, Gupta R, Gulati S, Munjal YP \& Concensus Group (2009), Consensus statement for diagnosis of obesity, abdominal obesity and the Metabolic Syndrome for Asian Indians and Recommendations for Physical activity, medical and surgical management. Journal of Association of Physicians of India 57, 163-170.

[18]Qureshi N, Armstrong S, Dhiman P, Saukko P, Middlemass J, Evans PH, Kai J \& ADDFAM study group (2012), Effect of Adding System- atic Family History Enquiry to Cardiovascular Disease Risk Assessment in Primary Care: A Matched-Pair, Cluster Randomized Trial. Ann Intern Med. 156, 253-262.

[19]Sesso HD, Lee IM, Gaziano JM, Rexrode KM, Glynn RJ \& Buring JE (2001), Maternal and Paternal History of Myocardial Infarction and Risk of Cardiovascular Disease in Men and Women. Circulation 104 393-398.

[20]Sheerin I, Hamilton G, Humphrey A \& Scragg A (2007), Issues in the assessment of cardiovascular risk in selected general practices in Canterbury, New Zealand. New Z Med J. 120, U2714.

[21] Tavaresa P, Oliveiraa A \& Lopes C (2011), Family history of coronary heart disease, health care and health Behaviours. Rev Port Cardiol. 30, 703-710.

[22]Van der Sande MAB, Walraven GEL, Milligan PJM, Banya WAS, Ceesay SM, Nyan OA \& McAdam KPWJ (2001), Family history: an opportunity for early interventions and improved control of hypertension, obesity and diabetes. Bulletin of the World Health Organization 79, 321-328

[23]Williams CJ, Hu FB, Patel SR \& Mantzoros CS (2007), Sleep Duration and Snoring in Relation to Biomarkers of Cardiovascular Disease Risk among Women with Type 2 Diabetes. Diabetes care 30, 1233 1240 .

[24]World Heart Federation. Accessed from http://www.world-heartfederation.org/cardiovascular-health/cardiovascular-disease-riskfactors/family-history/ on March 3, 2014.

[25]Zlot AI, Valdez R, Han Y, Silvey K \& Leman RF (2010), Influence of Family History of Cardiovascular Disease on Clinicians' Preventive Recommendations and subsequent adherence of patients without cardiovascular disease. Public Health Genomics 13, 457-466. 